〈연구논문(학술)〉

페놀계 모델 화합물 및 폴리벤조옥사진 수지에 대한 수소결합분포의 정량화

\author{
김호동 ${ }^{\dagger}$ 문화연
}

단국대학교 파이버시스템공학전공

\title{
Quantification for the Distribution of Hydrogen Bonding Species in Phenolic Model Compounds and Polybenzoxazines
}

\author{
HoDong $\mathrm{Kim}^{\dagger}$ and HwaYeon Moon
}

Dept. of Fiber System Engineering, Dankook University, Yongin-si 448-701, Korea

(Received: July 8, 2008/Revised: August 5, 2008/Accepted: August 20, 2008)

\begin{abstract}
To understand the complex hydrogen bonding structure, several phenolic derivatives and benzoxazine model compounds are synthesized and characterized by Fourier transform infrared spectroscopy (FT-IR). The estimation of molar extinction coefficients for various types of hydrogen bonding species is systematically carried out by the curve-resolving of FT-IR spectra. The distribution of hydrogen bonding species in benzoxazine model dimers is quantitatively analyzed. It is revealed that benzoxazine dimers and BA-a polybenzoxazine are mainly composed of intramolecular interaction rather than intermolecular interaction.
\end{abstract}

Keywords: hydrogen bond, intermolecular interaction, intramolecular interaction, polybenzoxazine, phenol

\section{1. 서 론}

현대 산업사회의 다양한 섬유소재에 대한 기능 성의 요구 및 산업용 섬유의 발전은 섬유고분자 원 료제품의 합성에서부터 의류디자인의 설계까지 폭 넓은 연구를 필요로 하고 있다. 특히 눈에 띄게 발 전하고 있는 분야는 고성능 섬유가공제를 개발하 고자 하는 분야로 페놀 유도체를 이용한 코팅용 접 착제, 나노물질의 접착제, 복합재료 강화용 수지등 이 두드러지고 있으며 섬유직물의 고강도화, 방탄/ 방검 특성의 극대화를 위해 다양한 종류의 에폭시 수지 및 페놀, 비스페놀 수지 등이 폭 넓게 연구되 고 있다. 이러한 페놀 유도체의 특징은 반복 분자단 위마다 - $\mathrm{OH}$ 기가 존재하고 있어서 다양한 형태의 수 소결합을 형성한다는 점이다. 여러 형태의 수소결 합은 가공제의 친수성, 결합구조의 변화, 최종 물성 의 변화 등과 밀접한 관련이 있다. 하지만 페놀 유 도체들의 수소결합의 분포나 정량화는 다양한 종류 의 분자간(intermolecular) 및 분자내(intramolecular)
수소결합의 종류의 혼재뿐만 아니라 수소결합력 크 기의 강약이 넓게 분포하고 있어서 가공제 및 고분 자 물질의 정량화를 단순한 기기분석을 통해 달성 하기는 매우 어렵다 ${ }^{1,2)}$.

유기화합물이나 고분자 내에 존재하는 관능기 의 양은 FT-IR이나 Raman 스펙트럼을 분석함으 로써 정량적으로 관찰할 수 있다는 사실은 매우 잘 알려져 있다 ${ }^{3)}$. 즉, 이러한 방법은 각 관능기에 대한 특성피크가 잘 알려져 있고 각 구성성분의 농도를 스펙트럼의 흡광율과 연관시켜 보정한 흡 광계수(molar extinction coefficient)를 알고 있다면 Beer-Lambert의 법칙을 이용해 매우 정확하게 관 능기의 양을 구할 수 있는 방법이다. 따라서 다 양한 형태의 수소결합을 형성하는 하이드록실기 $(-\mathrm{OH})$ 와 같은 경우에도 -OH stretching 주파수인 $3700-2500 \mathrm{~cm}^{-1}$ 에 나타나는 특성피크를 관찰함 으로써 각 수소결합 형태에 따른 분포를 알아볼 수 있으리라 판단된다.

하지만 다른 관능기와는 달리 $-\mathrm{OH}$ 기의 경우

${ }^{\dagger}$ Corresponding author. Tel.: +82-31-8005-3562; Fax.: +82-31-8005-3561; e-mail: hodong@dku.edu 
에는 (1) 수소결합 형태에 따라 -OH stretching 주파수가 낮은 주파수쪽으로 뚜렷한 차이 없 이 연속적으로 이동하는 경우가 많고, (2) 특정피 크의 반가폭(half-width)이 증가하여 피크의 모양이 완만해지며, (3) 특히 같은 양의 -OH기의 농도라 할지라도 수소결합 형태에 따라 흡광계수의 값이 몇 배 이상 차이가 나기 때문에 같은 분자내에 여 러 종류의 수소결합이 혼재할 경우 정량적인 분석 이 매우 어렵다고 알려져 있다)

가장 복잡한 형태의 수소결합을 형성하는 페놀 계 고분자는 Novolac계열의 epoxy수지를 아민류의 경화제로 경화시킨 경우(Scheme 1a)나 최근에 많 이 연구되고 있는 페놀계 polybenzoxazine(Scheme 1b) 수지류를 들 수 있다. 특히 polybenzoxazine 수 지류는 기존의 페놀수지의 단점을 극복하기 위해 최근 활발히 연구되고 있는 새로운 페놀유도체 수 지로 Ishida 등 ${ }^{5-8)}$ 을 중심으로 활발히 연구되고 있 다. 이 polybenzoxazine은 우수한 기계적인 강도,6) 및 사용 공정상의 용이성글 가지며 높은 난연성( 을 보이는 등 페놀수지의 장점을 그대로 가지고 있어서 그 활용도가 매우 크다고 알려져 있다. 하 지만 수지의 경화에 따른 분자구조의 해석 등에 대해서는 아직도 미흡한 점이 많으며, 특히 수소결 합 형태 및 분포에 대한 해석은 많지 않다 ${ }^{5,8,9)}$. 이 러한 이유로는 일단 경화된 수지는 열에 의해 재 용융되거나 용제에 의해 용해되지 않는 열경화성 고분자의 고유한 특징 때문에 기기분석이 매우 제 한적일 뿐만 아니라, 가교 고분자내의 수소결합 형태 및 분포가 복잡하기 때문이다.

따라서 본 연구에서는 체계적이며 논리적인 방 법으로 페놀계 유도체 및 모델화합물을 합성하고 그것들의 FT-IR을 분석함으로써 수소결합 분 포를 정량화 할 수 있는 방법을 제안하고자 하 였다. 또한 그러한 방법을 통해 특징적인 polybenzoxazine 수지내의 수소결합 분포를 정량화하 고, 얻어진 결과를 기존의 경화구조에 대한 연구
결과와 비교함으로써 새로운 수지 조성물의 합 성에 대한 기초적인 자료를 제공하고자 하였다.

\section{2. 실 험}

\section{1 시약}

모델 화합물들과 benzoxazine 단량체의 합성을 위해서 2,4-dimethylphenol (98\%), benzylbromide (98\%), bisphenol-A (97\%), p-formaldehyde (95\%), aniline (99\%), methylamine (40\% 수용액), t-butylamine (98\%), cyclohexylamine (98\%), salicylaldehyde (98\%), N-methylbenzylamine $(97 \%)$ 를 사용하였다. 상기에 사용된 모든 시약은 Aldrich사에서 구입하여 더 이상의 정제없이 그대로 합성반응에 사용하였다. Formaldehyde (37\% 수용액)는 Fisher Scientific에 서 구입한 시약을 그대로 사용하였다. 또한 FT-IR 분석을 위한 용제인 $\mathrm{CCl}_{4}$ (Carbon tetrachloride, HPLC급)는 Aldrich사에서 구입하여 사용하였다.

\section{2 페놀계 모델 화합물 및 폴리벤조옥사 진의 합성}

체계적인 수소결합 구조의 변화를 조사하기 위해 다양한 종류의 페놀계 모델 화합물들을 이전 연구 에서 얻어진 방법과 조건에 따라 합성하였다 ${ }^{9-11)}$. 또 한 bifunctional benzoxazine 단량체의 합성 및 정제는 Ning과 Ishida ${ }^{12}$ 와 Kim과 Ishida ${ }^{13)}$ 의 방법에 따랐으 며, 그 구조 및 표기방법을 Table 1에 나타내었다. 합성된 단량체는 추가적인 촉매나 개시제 없이 oxazine ring의 개환반응을 위해 $150^{\circ} \mathrm{C}-1 \mathrm{~h}, 175^{\circ} \mathrm{C}-1 \mathrm{~h}$, 그리고 $195{ }^{\circ} \mathrm{C}-2 \mathrm{~h}$ 의 단계적인 승온에 의해 열경화시 켰다(Scheme 2).

\subsection{FT-IR 분석 및 Curve fitting}

적외선분광분석(Fourier Transform InfraRed, FTIR) 스펙트럼은 액체질소로 냉각시킨 mercury-cadmiumtelluride (MCT) detector를 장치하고 있는 Bomem Michelson

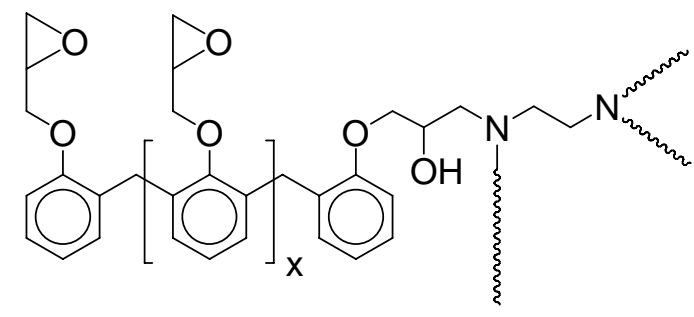

(a)

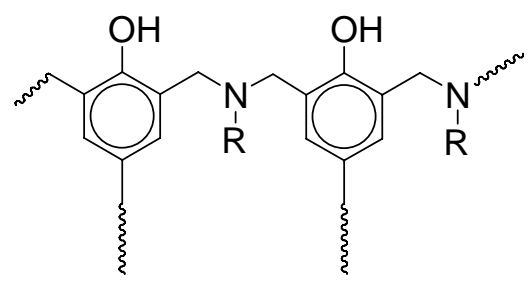

(b)

Scheme 1. Structures for typical phenolic resins. 

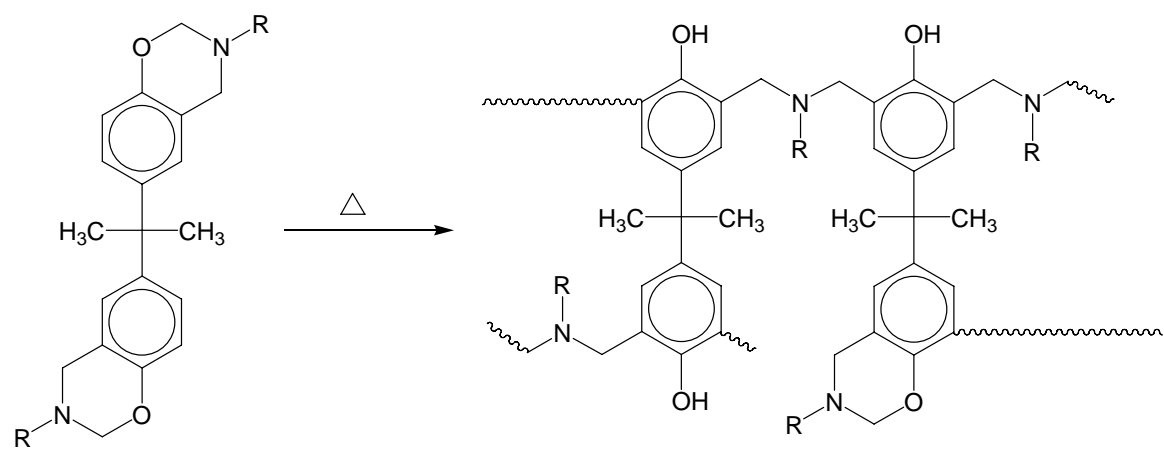

Scheme 2. Ring opening polymerization of bifunctional benzoxazine monomer.

Table 1. Structures of the phenolic model compounds

\begin{tabular}{|c|c|c|}
\hline Abbreviations & Chemical structures & IUPAC chemical names \\
\hline (I) Phenol & & Phenol \\
\hline (II) Benzyl phenol & & 2-benzyl-4,6-dimethylphenol \\
\hline (III) Phenolic dimer & & 2,2'-methylene-4,4',6,6'-tetramethyldiphenol \\
\hline (VI) Methyl-dimer & & N,N-bis(3,5-dimethyl- 2-hydroxybenzyl)methylamine \\
\hline (V) Aniline-dimer & & N,N-bis(3,5-dimethyl- 2-hydroxybenzyl)aniline \\
\hline \multirow[t]{2}{*}{ (VI) BA-a monomer } & & $\begin{array}{l}\text { 2,2-bis(3,4-dihydro-3-phenyl- } \\
\text { 2H-1,3-benzoxazine)propane }\end{array}$ \\
\hline & \multicolumn{2}{|l|}{$\mathrm{R}=-\mathrm{C}_{6} \mathrm{H}_{5}$} \\
\hline
\end{tabular}

MB110 FT-IR spectrophotometer를 이용하여 얻었 다. 모든 시료의 스펙트럼은 20 분간 질소기체로 purge한 후, $2 \mathrm{~cm}^{-1}$ 의 resolution으로 128 scan하여 얻었다. $\mathrm{KBr}$ pellet법에 의해 스펙트럼을 얻는 경우, $\mathrm{KBr}$ 분말내의 수분에 의해 발 생하는 피크와
본 연구에서 관찰하고자 하는 -OH stretching 영역 과 겹치는 현상이 발생하기 때문에 모든 분말시 료의 $\mathrm{FT}-\mathrm{IR}$ 스펙트럼은 두 장의 $\mathrm{KBr}$ 판 사이에 얇은 분말시료 층을 형성시킨 후 측정하였다. $\mathrm{CCl}_{4}$ 에 희석시킨 $10 \mathrm{mM}, 20 \mathrm{mM}$ 및 $50 \mathrm{mM}$ 의 모델물 
질들에 대한 용액 스펙트럼은 $0.5 \mathrm{~mm}$ 의 path length 를 가진 KRS-5 liquid cell을 이용하여 측정하였고 $1 \mathrm{mM}$ 과 $5 \mathrm{mM}$ 의 용액에 대해서는 $5 \mathrm{~mm}$ 의 path length를 가진 barium fluoride liquid cell을 이 용하여 측정하였다.

또한 $2000 \mathrm{~cm}^{-1}$ 에서 $4000 \mathrm{~cm}^{-1}$ 까지의 영역에서 중첩되어 나타나는 수소결합영역의 FT-IR spectrum 을 분리하기(curve-resolve) 위하여 Lorentzian-Gaussian 혼합함수를 적용시킨 GRAMS/32 (Galactic software, USA)를 사용하였다.

\section{3. 결과 및 고찰}

3.1 수소결합 형태에 따른 흡광계수의 결정

분자쇄내에 질소를 함유하고 있는 페놀화합물들 은 수소결합 가능한 질소의 존재로 인해 다양한 형태의 $-\mathrm{OH}$ 기가 존재할 수 있다. 즉, 수소결합에 참여하고 있지 않은 자유 $-\mathrm{OH}$ 기, 다른 분자의 $-\mathrm{OH}$ 기 사이의 분자간 $-\mathrm{OH} \cdots \mathrm{O}$ 수소결합, 동일한 분자내에서 형성되는 - $\mathrm{OH}$ 기 사이의 분자내 - $-\mathrm{OH}^{\cdots} \cdots$ $\mathrm{O}$ 수소결합 및 $-\mathrm{OH} \cdots \pi$ 수소결합, 그리고 $-\mathrm{OH}$ 기 와 $\mathrm{N}$ 사이에 형성되는 분자내 또는 분자간 - $\mathrm{OH}^{\cdots} \cdot$ $\mathrm{N}$ 수소결합이 존재한다. 서론에서 언급한 바와 같 이 다른 형태의 수소결합에 대한 흡광계수를 구할 수 있다면 좀 더 정확한 수소결합 분포를 예측할 수 있다고 생각된다.

분자간 수소결합을 하는 단순한 화합물인 (I) phenol을 $\mathrm{CCl}_{4}$ 에 희석시킨 용액의 FT-IR 스펙트 럼을 Fig. 1에 나타내었다. 페놀의 -OH기와 상호 작용이 적은 비극성용매인 $\mathrm{CCl}_{4}$ 에 아주 낮은 농도 인 $1 \mathrm{mM}$ 로 희석시킨 페놀의 FT-IR 특성피크는 sharp한 형태의 밴드를 $3615 \mathrm{~cm}^{-1}$ 근처에서 나타내 고 있다(Fig. 1a). 이러한 낮은 농도에서는 페놀 분 자간의 거리가 매우 멀어져서 $-\mathrm{OH}$ 기 사이의 수소 결합이 일어날 가능성이 매우 낮기 때문에 3615 $\mathrm{cm}^{-1}$ 의 sharp한 밴드는 결합되지 않은 자유로운 $-\mathrm{OH}$ 기에 의한 스펙트럼으로 알려져 있다. 하지만 좀더 페놀의 농도를 높이면 분자간의 거리가 가까 워지면서 분자간 수소결합(intermolecular hydrogen bond)이 가능해 지고 그에 따른 특성 피크가 3350 $\mathrm{cm}^{-1}$ 근처에서 매우 크고 broad한 밴드로 나타나고 있다(Fig. 1b). 이러한 두 종류의 -OH기들에 대한 스펙트럼을 각각의 형태대로 분리하여 그 면적을 구한다면 다음의 (1)식 ${ }^{2,14}$ 에 의하여 흡광계수를 구할 수 있다.

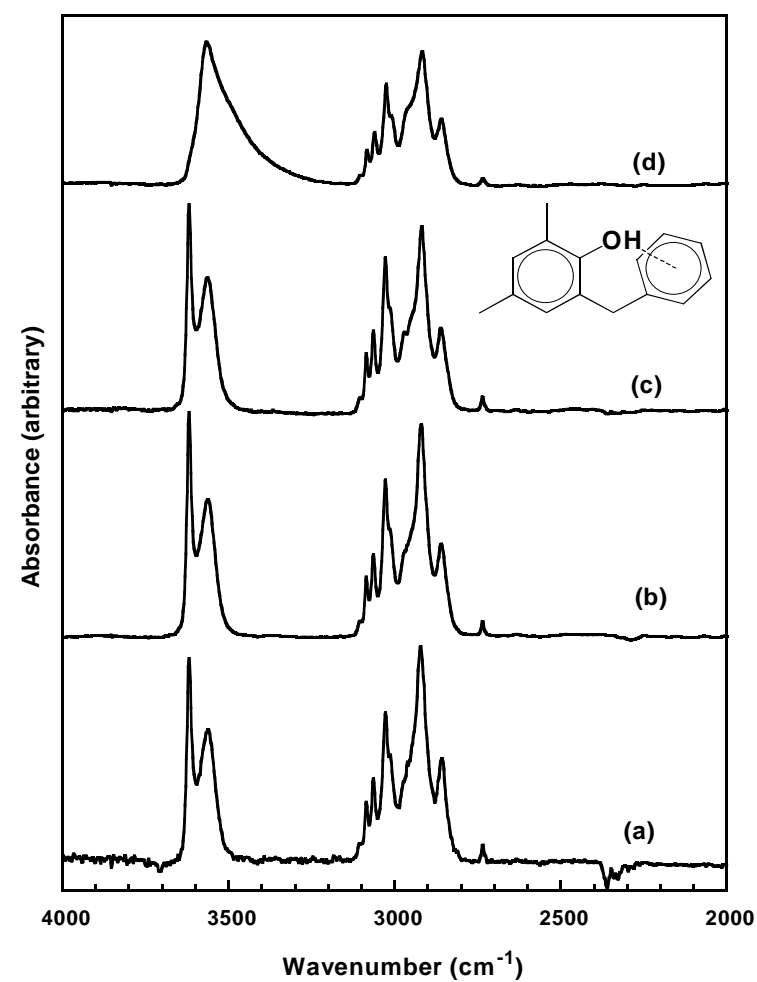

Fig. 1. Changes of the hydrogen bonding species in phenol diluted in $\mathrm{CCl}_{4}$. (a) $3 \mathrm{mM}$ and (b) $500 \mathrm{mM}$

$S=\int A d v=\varepsilon c l$

where, S: area of absorption,
A: absorbance,
$v$ : frequency,
e: molar absorption coefficient,
$c$ : concentration of solution, and
$l$ : path length of the cell.

먼저 분자간의 수소결합이 나타나지 않는 수 준의 매우 낮은 농도들의 FT-IR 스펙트럼으로부 터 수소결합에 의해 구속되지 않은 자유 - $\mathrm{OH}$ 기 에 대한 흡광계수를 산출해 내고, 그 값들을 농 도에 대해 도식화한 그래프의 $\mathrm{y}$-절편 값, 즉 농도 가 0 일때의 겉보기흡광계수 $\left(\varepsilon_{\mathrm{free}}\right)$ 를 외삽에 의해 구할 수 있었다(Fig. 2a). 다음으로 두 종류의 흡 광밴드를 보이는 고농도에서의 FT-IR스펙트럼을 curve fitting에 의해 분리한 후, 위에서 구한 $\varepsilon_{\text {free }}$ 를 이용하여 자유 -OH기의 농도 $\left(c_{\mathrm{free}}\right)$ 를 구할 수 있었다. 이 경우 분자간 수소결합에 참여하고 있 는 $-\mathrm{OH}$ 기의 양 $\left(c_{\mathrm{inter}}\right)$ 은 전체 농도 $\left(c_{0}\right)$ 에서 자유 $-\mathrm{OH}$ 기의 농도 $\left(c_{\mathrm{free}}\right)$ 를 뺀 값이므로 분자간 수소 결합에 의한 흡광계수 $\left(\varepsilon_{\mathrm{inter}}\right)$ 를 $\varepsilon_{\mathrm{free}}$ 의 경우와 마 찬가지로 구할 수 있었다(Fig. 2b). 


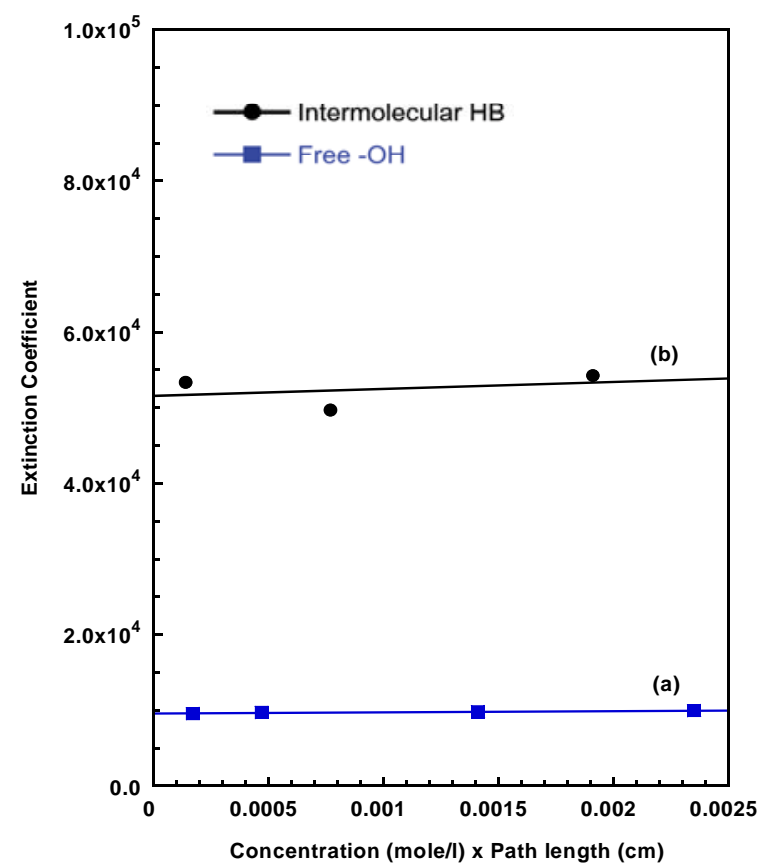

Fig. 2. Molar extinction coefficients for hydrogen bonding species in phenol diluted in $\mathrm{CCl}_{4}$. (a) Free $-\mathrm{OH}$ group and (b) Intermolecular hydrogen bond.

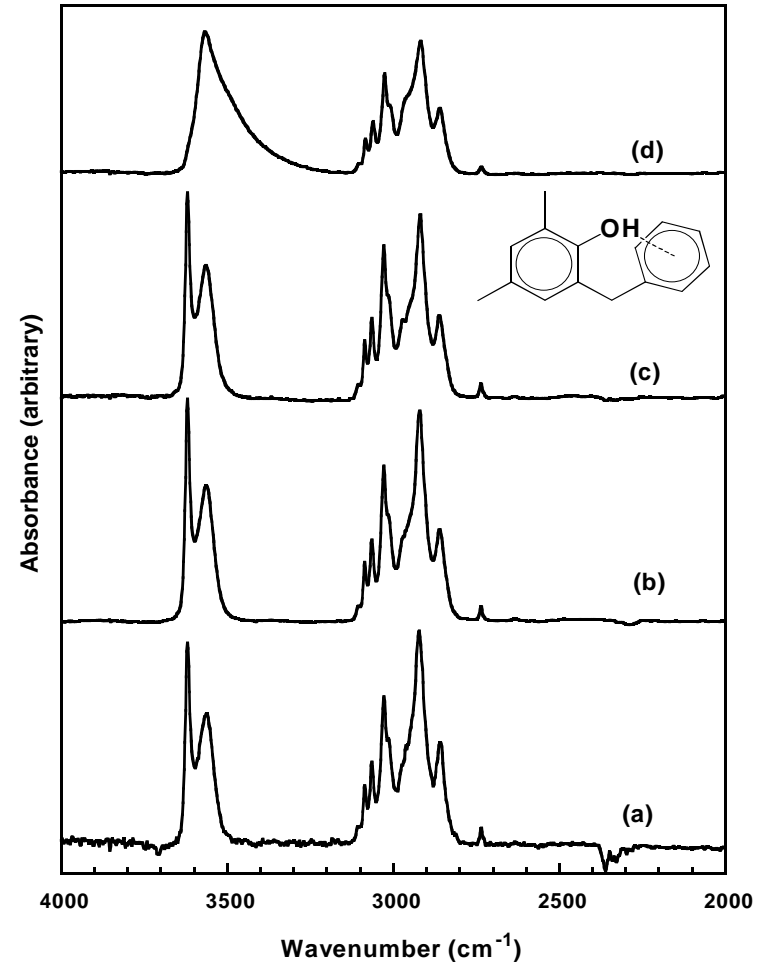

Fig. 3. Changes of the hydrogen bonding species in benzyl phenol diluted in $\mathrm{CCl}_{4}$. (a) $1 \mathrm{mM}$, (b) $10 \mathrm{mM}$, (c) $50 \mathrm{mM}$, and (d) pure liquid.

$$
\begin{gathered}
c_{\text {free }}=S /\left(\varepsilon_{\text {free }} \times l\right) \\
c_{\text {inter }}=c_{o}-c_{\text {free }}
\end{gathered}
$$

where, $c_{\mathrm{o}}=$ total concentration of $-\mathrm{OH}$ groups
페놀계 화합물에서 나타날 수 있는 흥미로운 수소결합 형태는 - $\mathrm{OH}$ 기와 벤젠고리 사이에서 일 어나는 $-\mathrm{OH} \cdots \pi$ 수소결합이다. 이러한 형태의 수 소결합에 대한 흡광계수를 구하기 위해 (II) benzyl phenol을 $\mathrm{CCl}_{4}$ 에 희석시킨 용액의 FT-IR 스펙트럼 을 Fig. 3에 나타내었다. 이때, benzyl phenol의 분자구조로부터 추측 가능한 수소결합의 형태는 자유 $-\mathrm{OH}$ 기 또는 분자간 수소결합이다. 하지만 농도가 바뀌어도 자유 - $\mathrm{OH}$ 기와의 상대적인 면적 비율이 변화하지 않는 점과 용제에 희석시키지 않은 순수한 benzyl phenol의 스펙트럼에서 매우 broad한 shoulder가 일반적인 분자간 수소결합에 의한 영역인 $3400 \mathrm{~cm}^{-1}$ 근처에서 나타나는 것으 로 미루어 볼 때, $3562 \mathrm{~cm}^{-1}$ 의 피크는 분자내 상 호작용(intramolecular interaction)에 의한 것으로 추정되었다. 유사한 형태의 분자내 수소결합를 Pimentel과 McClellan ${ }^{15)}$ 은 방향족 고리가 electron donor로써 작용하는 $-\mathrm{OH} \cdots \pi$ 수소결합으로 정의 하였으며, Cairns와 Eglinton ${ }^{16)}$ 은 novolac 화합물을 이 용한 실험을 통해 이러한 수소결합이 $3516 \mathrm{~cm}^{-1}$ 에서 나타남을 증명하고 $-\mathrm{OH} \cdots \pi$ 수소결합은 분 자내 원자들의 공간배치(conformation)와 밀접한 관계가 있다고 결론지었다. 따라서 $-\mathrm{OH} \cdots \pi$ 수 소결합으로 추정되는 - $\mathrm{OH}$ 에 대한 흡광계수 $\varepsilon_{0}$ $\mathrm{H} \cdots \pi$ 를 benzylic phenol의 FT-IR 스펙트럼으로부 터 $\varepsilon_{\text {inter }}$ 와 마찬가지 방법으로 구하였다.

또 하나의 모델 화합물은 한 분자내에 두 개의 $-\mathrm{OH}$ 기를 갖는 (III) phenolic dimer의 경우로 Fig. 4 에 농도별 FT-IR 스펙트럼을 나타내었다. 분자 구조에서 볼 수 있는 것처럼 phenolic dimer는 4 가지 형태의 $-\mathrm{OH}$ 기가 존재 할 수 있다(Scheme $3)$. 즉, (1) 분자간 수소결합 형태와 (2) 자유 -OH 기가 존재할 수 있으며 (3) $-\mathrm{OH} \cdots \pi$ 수소결합의 존재가 $3515 \mathrm{~cm}^{-1}$ 근처에서 작은 shoulder로 나타나 고 있다. 반면에 $3465 \mathrm{~cm}^{-1}$ 근처에서 나타나고 있 는 농도에 독립적인 피크는 $-\mathrm{OH} \cdots \pi$ 수소결합과 는 다른 종류의 분자내 상호작용(intramolecular interaction)에 의한 것으로 판단되며, 분자구조 및 논리적으로 (4) $-\mathrm{OH} \cdots \mathrm{O}$ 분자내 수소결합에 의한 것으로 추정된다. $20 \mathrm{mM}$ 의 스펙트럼에서 보이 는 매우 broad한 $3400 \mathrm{~cm}^{-1}$ 근처의 shoulder 피크 는 농도에 의존적인 형태와 FT- IR 흡광 주파 수로 볼 때 분자간 수소결합에 기인한 것으로 판단된다. 따라서 앞서 구한 3 가지의 흡광계수 $\left(\mathcal{E}_{\mathrm{free}}, \varepsilon_{\text {inter }}, \varepsilon_{\mathrm{OH} \cdots \pi}\right)$ 를 이용하여 $-\mathrm{OH} \cdots \mathrm{O}$ 분자내 


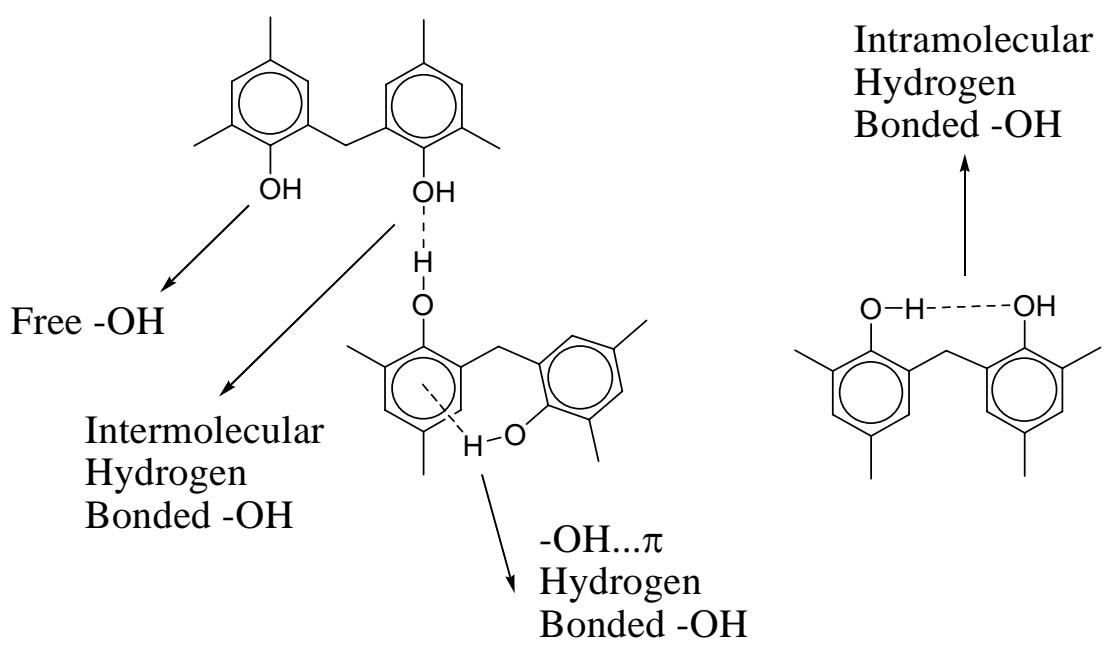

Scheme 3. Possible hydrogen bonded species in phenolic dimer.

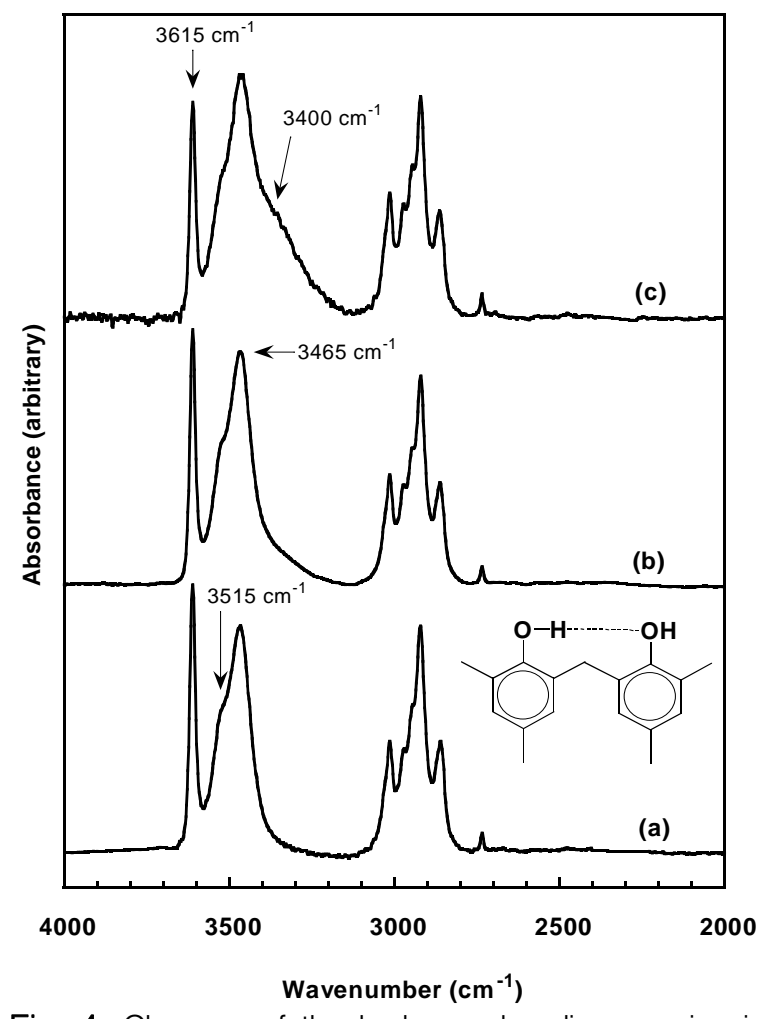

Fig. 4. Changes of the hydrogen bonding species in phenolic dimer diluted in $\mathrm{CCl}_{4}$. (a) $1 \mathrm{mM}$, (b) $5 \mathrm{mM}$, and (c) $20 \mathrm{mM}$

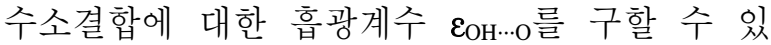
었다.

위에서 구한 각 수소결합 형태에 따른 $-\mathrm{OH}$ stretching에 대한 흡광계수들을 Table 2에 나타내 었다.

3.2 벤조옥사진 모델화합물의 수소결합 분포

용융이나 용해되지 않는 열경화성 고분자인 폴 리벤조옥사진의 구조분석을 위해 가장 단순한 기 본구조를 갖는 모델화합물 (IV) methyl dimer와 (V) aniline dimer를 합성하여 -OH stretching 영역 의 FT-IR 스펙트럼을 조사하였다. 또한 여러가지 수소결합에 의해 중첩된 스펙트럼을 앞서 구한 흡광계수와 흡광주파수를 이용하여 분리하고 각 수소결합종류들의 분율을 구하여 Table 3에 나타 내었다.

이러한 벤조옥사진 모델화합물에 추가된 또 하나의 수소결합 형태는 - $\mathrm{OH}$ 기와 아민의 질소간 에 형성되는 $-\mathrm{OH} \cdots \mathrm{N}$ 분자내 수소결합이다. 벤조 옥사진의 경우에 특징적인 구조인 Mannich bridge 와 페놀의 $-\mathrm{OH}$ 기간에 형성되는 이 수소결합은 안정적인 6-membered ring 형태를 형성하며, 아민

Table 2. Molar extinction coefficients for different hydrogen bonding species in model compounds

\begin{tabular}{ccc}
\hline Hydrogen bonding species & Frequency range $\left(\mathrm{cm}^{-1}\right)$ & Molar extinction coefficient $\left(1 / \mathrm{mole}^{\cdot} \mathrm{cm}^{2}\right)$ \\
\hline Free $-\mathrm{OH}$ & $3615 \sim 3611$ & $\varepsilon_{\text {free }}$ \\
\hline Intermolecular $-\mathrm{OH} \cdots \mathrm{O}$ & $3400 \sim 3360$ & $\varepsilon_{\text {interOH } \cdots \mathrm{O}}=51,559$ \\
Intramolecular $-\mathrm{OH} \cdots \pi$ & $3562 \sim 3548$ & $\varepsilon_{\text {intraOH } \cdots \pi}=10,427$ \\
Intramolecular $-\mathrm{OH} \cdots \mathrm{O}$ & $3468 \sim 3467$ & $\varepsilon_{\text {intraOH } \cdots \mathrm{O}}=38,308$ \\
\hline
\end{tabular}


Table 3. Distribution of hydrogen bonding in benzoxazine model dimers

\begin{tabular}{|c|c|c|c|c|c|c|}
\hline \multicolumn{2}{|c|}{ Hydrogen bonds } & Free $-\mathrm{OH}$ & $\begin{array}{c}\mathrm{OH} \cdots \pi \\
\text { intra }\end{array}$ & $\begin{array}{c}\mathrm{OH} \cdots \mathrm{O} \\
\text { intra }\end{array}$ & $\begin{array}{c}\mathrm{OH} \cdots \mathrm{O} \\
\text { inter }\end{array}$ & $\begin{array}{c}\mathrm{OH} \cdots \mathrm{N} \\
\text { intra }^{\text {(a) }}\end{array}$ \\
\hline \multirow{3}{*}{$\begin{array}{l}\text { MethylDi } \\
\text { mer }\end{array}$} & $\begin{array}{l}\text { Frequency } \\
\qquad\left(\mathrm{cm}^{-1}\right)\end{array}$ & 3615 & 3559 & 3467 & 3364 & $\sim 3000$ \\
\hline & $1 \mathrm{mM}$ & 0.08 & 0.06 & 0.11 & 0.02 & 0.74 \\
\hline & $50 \mathrm{mM}$ & 0.09 & 0.14 & 0.11 & 0.13 & 0.53 \\
\hline \multirow{3}{*}{$\begin{array}{l}\text { AnilineDi } \\
\text { mer }\end{array}$} & $\begin{array}{l}\text { Frequency } \\
\qquad\left(\mathrm{cm}^{-1}\right)\end{array}$ & 3613 & 3548 & 3467 & 3363 & $\sim 3000$ \\
\hline & $1 \mathrm{mM}$ & 0.10 & 0.22 & 0.01 & 0.06 & 0.61 \\
\hline & $50 \mathrm{mM}$ & 0.14 & 0.31 & 0.08 & 0.03 & 0.44 \\
\hline
\end{tabular}

(a) Fraction of $\mathrm{OH}^{\cdots} \mathrm{N}$ intra $=1-$ [total fraction for Free $-\mathrm{OH}, \mathrm{OH}^{\cdots} \pi$ intra, $\mathrm{OH}^{\cdots} \mathrm{O}$ intra, and $\mathrm{OH} \cdots \mathrm{O}$ inter]

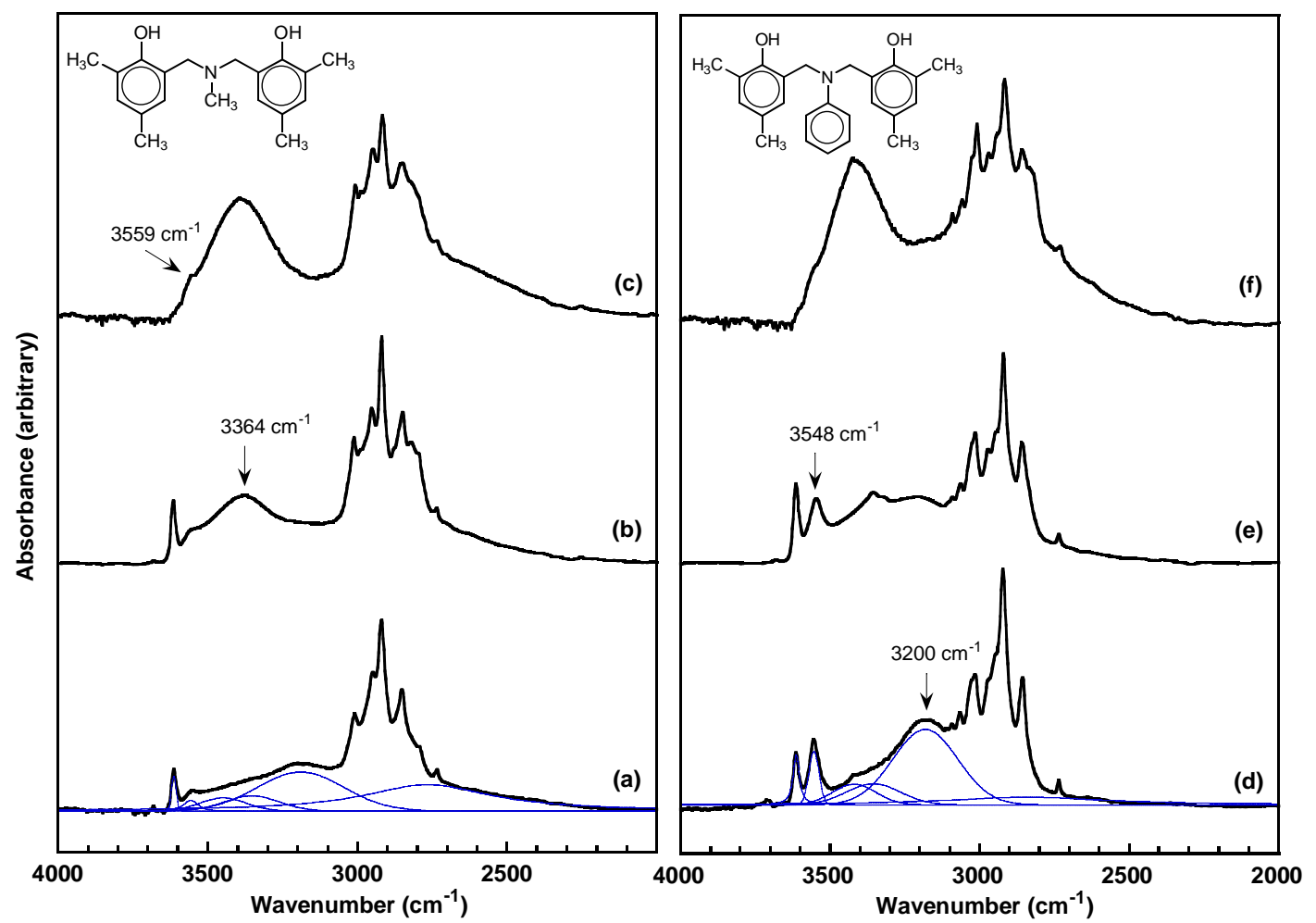

Fig. 5. Distribution of hydrogen bonds in Methyl dimer and Aniline dimer in $\mathrm{CCl}_{4}$ solution; (a) $1 \mathrm{mM}$ (Methyl dimer), (b) $50 \mathrm{mM}$ (Methyl dimer), and (c) Crystal (Methyl dimer), (d) $1 \mathrm{mM}$ (Aniline dimer), (e) $5 \mathrm{mM}$ (Aniline dimer), and (f) Crystal (Aniline dimer).

의 염기도에 따라 그 안정성이 크게 차이난다고 잘 알려져 있다 ${ }^{13)} .1 \mathrm{mM}$ 의 methyl dimer 용액에 대한 FT-IR 스펙트럼을 보면 이러한 현상이 잘 나타나 있다. 대부분의 -OH기 들은 분자내 수소 결합들을 형성하고 있으며, $-\mathrm{OH} \cdots \mathrm{O}$ 분자간 수소 결합은 분율 0.02 정도로 거의 나타나지 않고 있 다. 용액의 농도를 높인 Fig. $5 \mathrm{~b}$ 의 경우, $-\mathrm{OH} \cdots \mathrm{O}$ 분자간 수소결합에 대한 흡광주파수인 $3364 \mathrm{~cm}^{-1}$ 가 뚜렷이 증가하고 있는 현상을 나타내고 있다.
용액에 대한 스펙트럼이 아닌 methyl dimer 결 정분말에 대한 흡광스펙트럼(Fig. 5c)은 좀 더 고 분자의 수소결합 구조에 가까운 정보를 제공할 수 있다. 분자간 거리가 매우 가깝게 밀집되어 있는 결정의 경우, 자유로운 - $\mathrm{OH}$ 기들은 사라지 고 $3559 \mathrm{~cm}^{-1}$ 에 약간의 shoulder가 보이는 것 이 외에는 대부분의 $-\mathrm{OH}$ 기가 분자간 수소결합에 참 여하고 있으며, $3000 \mathrm{~cm}^{-1}$ 근방의 broad한 base line으로 특성지워지는 $-\mathrm{OH} \cdots \mathrm{N}$ 분자내 수소결합 
으로 구성되어 있음을 나타내고 있다. 이러한 $-\mathrm{OH} \cdots \mathrm{N}$ 분자내 수소결합은 $-\mathrm{OH} \cdots \mathrm{N} \leftrightarrow-\mathrm{O}^{-} \cdots \mathrm{H}^{+} \mathrm{N}$ 와 같은 $-\mathrm{OH}$ 기내의 수소가 질소원자와 빠르게 protonation되면서 약 $3200 \mathrm{~cm}^{-1}(-\mathrm{OH} \cdots \mathrm{N})$ 근방에 서부터 $2700 \mathrm{~cm}^{-1}\left(-\mathrm{O}^{-} \cdots \mathrm{H}^{+} \mathrm{N}\right)$ 근방까지 매우 broad 한 스펙트럼을 보인다고 잘 알려져 있다 ${ }^{17,18)}$.

Aniline dimer의 경우에도 유사한 경향을 나타 내고 있다. 다만 Fig. 5d에서 볼 수 있는 것처럼 $3548 \mathrm{~cm}^{-1}$ 부근의 $-\mathrm{OH} \cdots \pi$ 수소결합이 뚜렷하게 보이고 있으며, $3200 \mathrm{~cm}^{-1}$ 근방의 $-\mathrm{OH} \cdots \mathrm{N}$ 수소 결합에 대한 흡광밴드가 크게 확장되어 있는 것 을 볼 수 있다. 이러한 현상은 aniline dimer의 주 요 관능기인 phenyl 구조 도입에 따른 conformation 의 변화와 절대적인 벤젠고리의 양이 증가했기 때문으로 판단된다. $50 \mathrm{mM}$ 의 aniline dimer에 대 한 $-\mathrm{OH} \cdots \pi$ 수소결합 분율이 $0.31,-\mathrm{OH} \cdots \mathrm{N}$ 수소 결합 분율이 0.44 에 나타난 것처럼 model dimer 들의 경우 분자간 interaction보다는 분자내 interaction에 대부분의 $-\mathrm{OH}$ 기가 참여하고 있다는 사 실은 매우 흥미로운 점이며, 뒤에서 언급할 폴리 벤조옥사진의 수소결합구조를 유추하는데 매우 중요한 정보를 제공한다고 생각된다.
3.3 폴리벤조옥사진의 수소결합 분포 해석 과 경화구조

Fig. 6에 대표적인 폴리벤조옥사진 수지인 BA-a polybenzoxazine에 대한 FT-IR 스펙트 럼과 각 수소결합 형태에 따른 분율을 나타 내었다. 이때 매우 broad하여 각 수소결합 종 류가 분명하게 나타나지 않는 BA-a polybenzoxazine의 스펙트럼은 모델물질로부터 얻어진 각 수소결합 종류에 따른 흡광주파수를 적용한 curve-fitting 소프트웨어를 이용하여 분리하 였다. Polybenzoxazine 고분자 경화물은 용액상 에 분산된 벤조옥사진 모델 dimer의 수소결 합 형태보다는 고체상태의 순수 결정 분말에 대한 수소결합 형태에 좀 더 근접해 있다고 판단된다. 즉, 대부분의 자유 $-\mathrm{OH}$ 기는 사라지 고 대부분의 $-\mathrm{OH}$ 기가 $-\mathrm{OH} \cdots \pi$ 분자내 수소결 합(분율 0.13 )과 $-\mathrm{OH} \cdots \mathrm{N}$ 분자내 수소결합(분율 0.76)에 참여하고 있으며, 일부분이 $-\mathrm{OH} \cdots \mathrm{O}$ 분자간 수소결합(분율 0.09)에 참여하고 있다. 이러한 결과는 Scheme 2에 보여진 것과 같이 벤조옥사진 단량체가 화학적인 개환중합에 의해

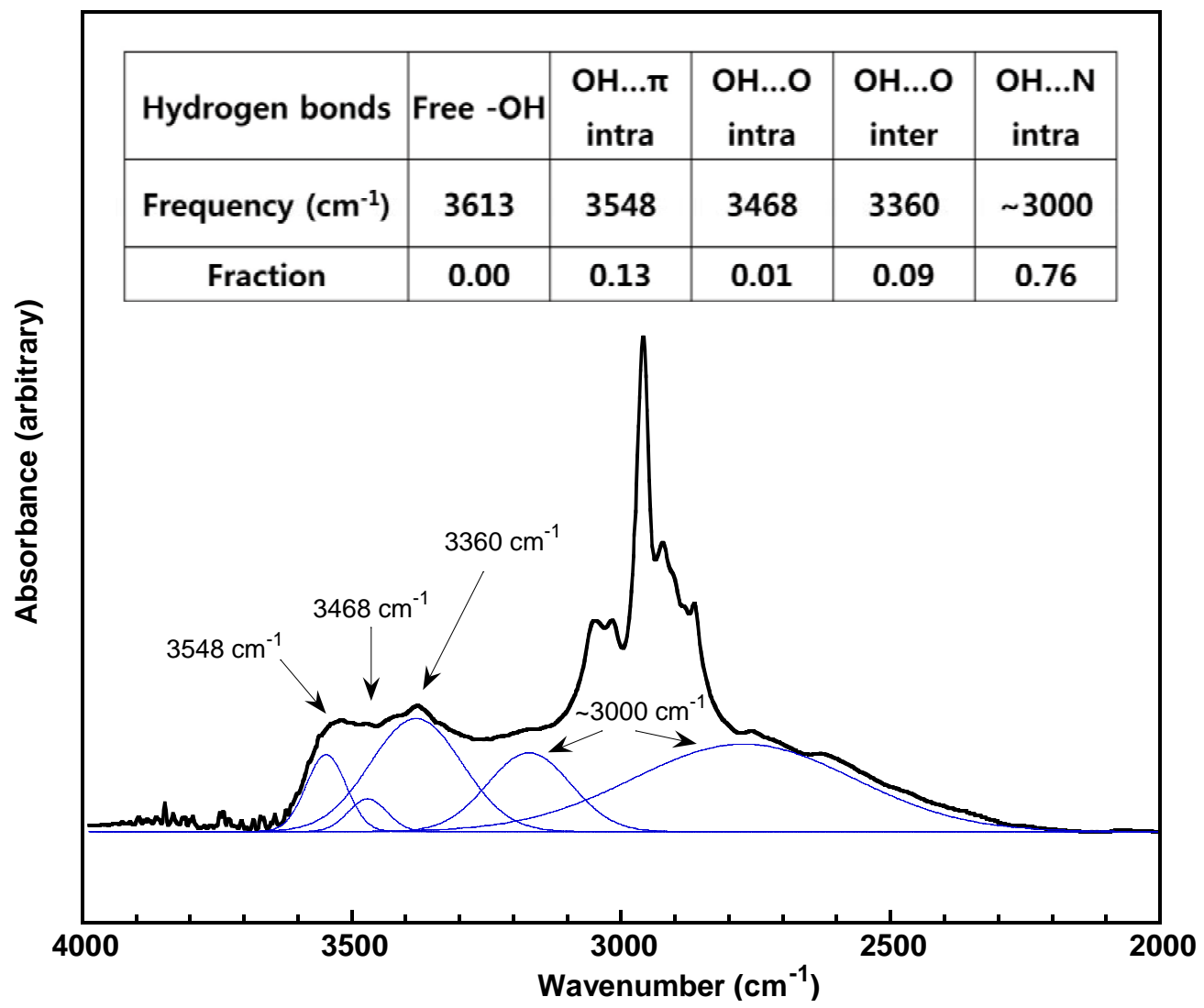

Fig. 6. Distribution of hydrogen bonding BA-a polybenzoxazine. 
가교구조가 형성될 때, 개환에 의해 발생되는 $-\mathrm{OH}$ 기가 계속적으로 안정적인 분자내 수소결 합을 형성함으로써 -OH기가 분자간 수소결합 에 참여하는 확률이 떨어지고 있음을 잘 나 타내고 있다.

폴리벤조옥사진의 가교구조에 대한 여러 연구 ${ }^{5,8-13)}$ 에 의하면 가교결합의 양이 매우 높아 우수 한 물리적 특성을 나타내는 기존의 페놀 수지와 는 달리 폴리벤조옥사진은 화학적인 가교결합의 양은 상당히 적다고 알려져 있다.

그럼에도 불구하고 폴리벤조옥사진이 페놀수 지보다 우수한 열적, 화학적인 안정성을 보이는 것은 수소결합에 의한 물리적인 가교결합이 큰 역할을 한다고 추정되고 있다. 이러한 추정을 Fig. 6에 보이는 것처럼 각 수소결합 형태에 대 한 분율을 알아봄으로써 보다 상세한 경화 구조에 대한 정보를 제공할 수 있다고 판단 된다.

\section{4. 결 론}

본 연구에서는 페놀계 화합물과 벤조옥사진 모델 화합물을 합성하고 그것들의 FT-IR을 분석 함으로써 수소결합 분포를 정량화 할 수 있는 방법을 제안하고자 하였다. 또한 본 연구에서 제 안된 방법을 사용하여 polybenzoxazine 경화물의 수소결합 분포를 재해석하여 다음과 같은 결과 를 얻었다.

페놀계 화합물 내에 존재하는 다양한 형태의 수소결합에 대한 적외선흡광계수를 산출하고, 같은 분자내에 존재하는 동일한 구조의 $-\mathrm{OH}$ 기 라 하더라도 참여하고 있는 수소결합 형태에 따 라 흡광계수의 값이 수배이상 차이남을 확인하 였다.

또한 벤조옥사진 모델 dimer와 폴리벤조옥 사진의 FT-IR 스펙트럼을 각 수소결합 형태에 대한 흡광계수를 이용하여 계산한 결과 $-\mathrm{OH}$ 기 대부분은 분자간 상호작용보다는 분자내 상호작용에 참여하고 있다는 결과를 확인하 였다.

$$
\text { 감사의 글 }
$$

이 연구는 2006학년도 단국대학교 대학연구비의 지원으로 연구되었음.

\section{참고문헌}

1. G. C. Pimentel and A. L. McClellan, "The Hydrogen Bond", W. H. Freeman and Company, London, pp.95-96, 1960.

2. C. M. Huggins and G. C. Pimentel, Systematics of the Infrared Spectral Properties of Hydrogen Bonding Systems: Frequency Shift, Half Width and Intensity, J. Phy. Chem., 60, 1615-1619(1956).

3. J. L. Koenig, "Spectroscopy of Polymers", American Chemical Society, Washington DC, pp.64-76, 1992.

4. G. C. Pimentel and A. L. McClellan, "The Hydrogen Bond", W. H. Freeman and Company, London, pp.68-70, 1960.

5. H. Ishida and D. J. Allen, Physical and Mechanical Characterization of Near-Zero Shrinkage Polybenzoxazines, J. Polym. Sci.: Polym. Phy., 34, 1019-1029(1996).

6. S. B. Shen and H. Ishida, Development and Characterization of High-Performance Polybenzoxazine Composites, Polym. Comp., 17, 710-719 (1996).

7. H. Ishida and Y. Rodriguez, Curing Kinetics of a new benzoxazine-based phenolic resin by DSC, Polymer, 36, 3151-3158(1995).

8. H. Ishida and H. Y. Low, A Study on the Volumetric Expansion of Benzoxazine-Based Phenolic Resin, Macromolecules, 30, 1099-1106 (1997).

9. H. D. Kim and H. Ishida, Study on the Chemical Stability of Benzoxazine-Based Phenolic Resins in Carboxylic Acids, J. Appl. Polym. Sci., 79, 1207-1219(2001).

10. H. D. Kim and H. Ishida, A Study on Hydrogen Bonded Network Structure of Polybenzoxazines, J. Phy. Chem. A, 106, 3271-3280(2002).

11. H. D. Kim and H. Ishida, A Study on Hydrogen Bonding in Controlled-Structure Benzoxazine Model Oligomers, Macromol. Sympo., 195, 123140(2003).

12. X. Ning and H. Ishida, Phenolic Materials via Ring-Opening Polymerization: Synthesis and Characterization of Bisphenol-A Based Benzoxazines and Their Polymers, J. Polym. Sci.: Polym. 
Chem. Ed., 32, 1121-1129(1994).

13. H. D. Kim and H. Ishida, compounds study on the network structure of polybenzoxazines, Macromolecules, 36, 8320-8329(2003).

14. L. R. Schroeder and S. L. Cooper, Hydrogen Bonding in Polyamides, J. Appl. Phy., 47, 43104317(1976).

15. G. C. Pimentel and A. L. McClellan, "The Hydrogen Bond", W. H. Freeman and Company, London, pp.202-203, 1960.

16. T. Cairns and G. Eglinton, Hydrogen Bond in Phenols part II, Alkyl Substituted Bis(hydroxyphenyl) alkanes, J. Chem. Soc., 5906-5913(1965).
17. M. Rospenk and T. Zeegers-Huyskens, Solvent Effect on the Intramolecular Hydrogen Bond Strength and on the Isotopic Ratio $v_{\mathrm{NH}+} / v_{\mathrm{ND}+}$ in a Trisubstituted Mannich Base, J. Phy. Chem., 91, 3974-3977(1987).

18. B. Brzezunski, H. Maciejewska, and G. Zundel, Proton Polarizability Due to Collective Proton Motion in Intramolecular Hydrogen-Bonded Systems in Monoperchlorates of 2,6-Bis((diethylamino) methyl)-4-R-phenol Di-N-oxides as a Function of the pKa of the Phenolic Group, J. Phy. Chem., 94, 6983-6986(1990). 